\title{
Matrix effects on the relative sensitivity factors for manganese and chromium during ion microprobe analysis of carbonate: implications for early Solar System chronology
}

\author{
Robert C. J. Steele ${ }^{\mathrm{a}, \mathrm{b}}$, Veronika S. Heber ${ }^{\mathrm{a}, \mathrm{c}}$, Kevin D. McKeegan ${ }^{\mathrm{a}}$ \\ ${ }^{a}$ Dept. of Earth, Planetary, and Space Sciences, University of California - Los Angeles, Los Angeles, CA. \\ 90095-1567, USA. \\ ${ }^{b}$ Now at: Institute of Geochemistry and Petrology, Department of Earth Sciences, ETH Zürich, Clausiusstrasse \\ 25, 8092 Zürich, Switzerland. Phone: +41 (0) 446338957 \\ ${ }^{c}$ Now at: Paul Scherrer Institut, 5232 Villigen PSI, Switzerland.
}

\begin{abstract}
The short-lived radionuclide ${ }^{53} \mathrm{Mn}$ decays to ${ }^{53} \mathrm{Cr}$ providing a relative chronometer for dating the formation of Mn-rich minerals in meteorites. Secondary ion mass spectrometry (SIMS) has been extensively used for in situ dating of meteoritic olivine and carbonate by the ${ }^{53} \mathrm{Mn}-{ }^{53} \mathrm{Cr}$ system, however a significant analytical challenge has been realising accurate measurements of the $\mathrm{Mn} / \mathrm{Cr}$ ratio in individual minerals of differing chemical compositions. During SIMS analysis, elements are ionised with differing efficiencies and standard materials are required to calibrate measured ion intensities in terms of relative elemental concentrations. The carbonate system presents a particular analytical difficulty since such standards are not naturally available due to low and variable $\mathrm{Cr}$ contents. Here, we utilise ion implantation of $\mathrm{Cr}$ into carbonate and other phases to accurately determine the relative sensitivity factors (RSFs) of Mn/Cr during SIMS analysis. We find significant variations in Mn/Cr RSF values among different carbonate minerals that depend systematically on chemical composition and we propose an empirical correction scheme that quantitatively yields an accurate RSF for carbonates of diverse chemical compositions. Correction of previous SIMS carbonate data for this strong matrix effect may help to reconcile some outstanding problems regarding the timescales of aqueous alteration processes in carbonaceous chondrites. $\mathrm{Mn}-\mathrm{Cr}$ ages, revised based our new understanding of the matrix effect, are, in general, earlier than previously thought and the duration of carbonate formation is shorter.
\end{abstract}


Keywords: Early Solar System chronology, ${ }^{53} \mathrm{Mn}, \mathrm{Cr}$ isotopes, Secondary Ion Mass Spectrometry, Relative Sensitivity Factor, Matrix Effect

\section{Introduction}

Secondary ion mass spectrometry (SIMS, or ion microprobe analysis) is a widely used analytical technique for in situ determination of isotopic ratios and trace element abundances. SIMS analysis is commonly applied to natural and synthetic samples at length-scales typically ranging from tens of micrometers to sub-micrometer. Compared to most other mass spectrometry methods, SIMS offers significant advantages where high spatial resolution and/or low blanks are a major priority (see Ireland, 1995, for a review). However, due to the nature of the sputtering process, ion yields in SIMS vary dramatically from one element to another. Measured ion ratios must therefore be corrected by a relative sensitivity factor (RSF) in order to compute accurate inter-element ratios in the sputtered volume of a given sample. In practical terms, this is addressed by analysing a standard material under instrumental conditions as similar to those used for the analysis of the unknown as is possible to achieve. The standard, whether natural or synthetic, must have a known concentration of the element of interest and it should be homogeneous at a scale larger than the scale of analysis. Ideally, it should also have the same bulk chemical composition and crystallographic structure as the analyte sample.

For many applications, well characterised minerals are readily available for use as standards, however in other cases, it can be nearly impossible to find (or difficult to produce) materials which are a close match to the analyte. In such cases, accuracy of analyses can be potentially compromised by uncalibrated differences in the RSF (for a given element or isotope ratio) between that determined on a standard and that appropriate for the unknown analyte. Such differences arise because sputtering and ionisation yields in SIMS depend on complex interactions of the primary ion beam with the matrix of the solid sample being analysed and hence are generically referred to as 'matrix effects'.

In this contribution, we focus on a solution to a particularly troublesome matrix effect that has vexed an important SIMS application: the use of the short-lived radionuclide ${ }^{53} \mathrm{Mn}$ (half-life of 3.7 Ma, Honda and Imamura, 1971) as a chronometer for dating the formation of carbonate minerals in the early solar system (Endress et al., 1994; Endress et al., 1996; 
Hutcheon et al., 1998; Hoppe et al., 2007; de Leuw et al., 2009; Petitat et al., 2011; Fujiya et al., 2012; Jilly et al., 2013; Fujiya et al., 2013). In general, the analytical requirement for determining the former abundance of any short-lived (now-extinct) radionuclide in an early solar system object is the demonstration of a spatial correlation of excesses of the daughter isotope with the parent to daughter elemental ratio (see McKeegan and Davis, 2003, for a discussion). Because ${ }^{53} \mathrm{Mn}$ decays to ${ }^{53} \mathrm{Cr}$, the inference of the initial ${ }^{53} \mathrm{Mn}$ abundance in a carbonate mineral is based on the slope of the correlation line between the ${ }^{53} \mathrm{Cr} /{ }^{52} \mathrm{Cr}$ isotope ratio and the ${ }^{55} \mathrm{Mn} /{ }^{52} \mathrm{Cr}$ elemental ratio. Here we show that SIMS measurements of this elemental ratio may be inaccurate by up to a factor of two over the range of carbonate compositions found in meteorites. This large matrix effect has not been previously documented because of the lack of availability of carbonate minerals with known, homogeneously distributed $\mathrm{Cr}$ impurities that can serve as standards. We quantify $\mathrm{Mn} / \mathrm{Cr}$ relative sensitivity factors for a range of carbonate mineral compositions by the method of ion implantation (Leta and Morrison, 1980; Burnett et al., 2015) and suggest implications for early solar system chronology.

\subsection{SIMS Relative sensitivity factors for $\mathrm{Mn} / \mathrm{Cr}$ ratios}

The RSF is defined here as the scaling factor that multiplies measured ion ratios to derive relative concentrations:

$$
\mathrm{RSF}=\frac{C_{a} / C_{b}}{I_{a} / I_{b}}
$$

where the subscripts $a$ and $b$ denote elements a and $\mathrm{b}$, respectively, and $\mathrm{C}_{x}$ represents the true concentration of the element and $\mathrm{I}_{x}$ the measured signal intensity during SIMS analysis. This factor must be measured under the same conditions as the measurement of the unknowns, but once determined to sufficient precision it does not need to be repeated as long as the conditions of analysis are stable. There were early efforts to theoretically determine the sensitivities for analyses, however, due to the complexity of the sputtering process, these were found to be less accurate than empirical determination based on calibrated standards (Smith and Christie, 1978).

\subsection{Previous studies of $\mathrm{Mn} / \mathrm{Cr} \mathrm{RSF}$ for $\mathrm{Mn}$-Cr dating}

In order to maximise the isotopic shift due to decay of the radiogenic parent isotope, materials with very high parent to daughter ratios are chosen for analysis. Thus, for $\mathrm{Mn} / \mathrm{Cr}$ 
dating minerals are chosen which preferentially incorporate $\mathrm{Mn}$, possibly as a major lattice forming element, and exclude $\mathrm{Cr}$ from the crystal structure.

Numerous studies have examined the $\mathrm{Mn} / \mathrm{Cr}$ chronologies of meteoritic olivine (Glavin et al., 2004; Sugiura et al., 2005; Ito and Ganguly, 2006; Matzel et al., 2009; McKibbin et al., 2013a,b) and carbonate (Endress et al., 1994; Endress et al., 1996; Hutcheon et al., 1998; Hoppe et al., 2007; de Leuw et al., 2009; Petitat et al., 2011; Fujiya et al., 2012; Jilly et al., 2013; Fujiya et al., 2013). These studies provide a good illustration of the problems associated with RSF calibration and the different approaches employed to obtain relative $\mathrm{Mn} / \mathrm{Cr}$ chronologies.

Although use of the $\mathrm{Mn} / \mathrm{Cr}$ chronometer in meteoritic olivine has a long history (e.g. Hutcheon et al., 1998) a systematic investigation of the Mn/Cr RSF in olivine has been undertaken only recently (Matzel et al., 2009; McKibbin et al., 2013b). McKibbin et al. (2013b) investigated the variation in $\mathrm{Mn} / \mathrm{Cr} \mathrm{RSF}$ in olivine using the SHRIMP-RG (Ireland et al., 2008) by analysing $\mathrm{Mn} / \mathrm{Cr}$ ratios in different olivines ranging from forsteritic to more fayalitic compositions. Interestingly, McKibbin et al. (2013b) and Doyle et al. (2016) found significant variation in the $\mathrm{Mn} / \mathrm{Cr} \mathrm{RSF}$, up to $\sim 50 \%$, between different compositions of olivine. This underlines the importance of systematically investigating the variation in the $\mathrm{Mn} / \mathrm{Cr} \mathrm{RSF}$ in meteoritic carbonates, which generally exhibit more compositional complexity than does the Fe-Mg solid solution series in olivine. Unfortunately, for the reasons discussed below, appropriate natural standards do not exist and synthesis of carbonates with uniform $\mathrm{Cr}$ contents is difficult so the approach of McKibbin et al. is not generally viable for carbonates.

\section{3. $\mathrm{Mn} / \mathrm{Cr} \mathrm{RSF}$ in carbonates}

Some carbonates preferentially incorporate $\mathrm{Mn}$ as a matrix element at percent levels, while excluding $\mathrm{Cr}$ to only trace amounts, resulting in ratios that can reach the $10^{6}$ range. This magnitude of parent/daughter ratios yields large anomalies in the $\mathrm{Cr}$ isotope composition meaning that the age, or $\left({ }^{53} \mathrm{Mn} /{ }^{55} \mathrm{Mn}\right)_{0}$ ratio, can generally be determined very precisely by SIMS.

Hoppe et al. (2007) attempted to determine the Mn/Cr RSF by direct measurement of synthetic carbonates, and while the $\mathrm{Cr}$ concentration could be precisely determined by bulk methods, individual carbonate grains were found to be highly heterogeneous on the scale of a few microns when examined by SIMS, leading to a significant imprecision in the resulting RSF. 
Thus, determining a $\mathrm{Mn} / \mathrm{Cr}$ ratio that is appropriate for SIMS corrections by a bulk method is extremely challenging because of the low and highly heterogeneous $\mathrm{Cr}$ concentration of available carbonates (e.g. Hoppe et al., 2007). This means that the imprecision in determining RSF values can mask potential systematic uncertainties due to matrix effects. Regardless of the precision achieved for an isochron measured on a series of grains of a given carbonate mineral, even if they vary widely in $\mathrm{Mn} / \mathrm{Cr}$ ratios, unless the RSF is accurately known, the ages deduced from these isotopes may be systematically incorrect.

More significantly though, there may be variations in the matrix effect between carbonates of different bulk composition. This would mean that currently only ages from carbonates with the same bulk composition could be considered together. Because of the lack of suitable carbonate standards from which to determine a RSF, many previous studies used the $\mathrm{Mn} / \mathrm{Cr}$ RSF determined from silicate standards (principally olivine) to estimate that of carbonate. Clearly, the use of a single RSF to correct $\mathrm{Mn} / \mathrm{Cr}$ matrix effects not only ignores the possibility of a different matrix effect between carbonates and silicate, but also variation in RSF between carbonates of different compositions. This problem was appreciated by previous investigators (e.g. Endress et al., 1996; Hutcheon et al., 1998), but it was hoped that matrix effects between olivine and carbonate would be relatively small (tens of percent at most) and constant among carbonates of various composition. If the latter condition applied, then it was reasoned, that all carbonate ages might be inaccurate relative to silicate ages by some fixed factor, but among carbonates the timescales deduced would have relative accuracy. That is, carbonates of different compositions would have ages that were inaccurate by the same scaling factor (e.g., Petitat et al., 2011). Documented variations in the $\mathrm{Mn} / \mathrm{Cr} \mathrm{RSF}$ between different carbonate compositions would therefore call into question the accuracy of such ages.

\section{Relative sensitivity factors by ion implantation}

The fundamental requirement for any standard useful for SIMS is that abundances of the elements in question be known as a function of spatial coordinate. For major elements (e.g., $\mathrm{Mn}$ ), concentrations and possible zonation can be determined by electron microprobe methods, however, this is typically not possible for $\mathrm{Cr}$ in carbonates because of detection limits. Thus, what is required is a suite of samples with known, homogeneously distributed $\mathrm{Cr}$ con- 
centrations. Such samples can be readily produced by the method of ion implantation (Zinner and Walker, 1975; Leta and Morrison, 1980; Burnett et al., 2015). In effect, ion implantation is analogous to isotope dilution for determining concentrations (Inghram, 1954). A series of sample materials can be implanted simultaneously which results in a single concentration for the implant. The major requirements with this approach are that the concentration of the implanted isotope must be significantly greater than the natural impurity levels in the standard material and the implant fluence must be accurately known, otherwise the errors will propagate directly into the RSF determination. Here we review some factors to consider in optimising the accuracy and utility of this method of standard development.

\subsection{Choosing the optimum implant characteristics}

There are several considerations when choosing the conditions under which the implant will be made. The first is which isotope to implant. From an analytical perspective it is preferable to implant a minor isotope because the precision of a background subtraction based the natural isotopic composition is thereby enhanced. However, for certain elements it is difficult to obtain an ion beam of high enough intensity to make ion implantation practical, meaning that a minor isotope may make the implant prohibitively time consuming (and thus expensive). However, implanting a major isotope, for which it is easier to achieve the required fluence, does not produce a net advantage because the required fluence also increases by the same fraction as the increase in the implanting signal in order to overcome the naturally occurring background abundance of the implanted isotope. Therefore, the most important consideration when choosing the implanted isotope is that it not be significantly interfered by unresolvable isobaric interferences during SIMS analysis.

The next considerations are the conditions of the implant itself: What energy should be used? What fluence is required to achieve the required precision? The energy of the implanted ions is an important factor because this controls the depth of the implant distribution. If the energy is too low, and the implant peak is in the top $\sim 50 \mathrm{~nm}$ of the sample, then contamination from the surface will likely interfere with, and possibly swamp, the measured implant profile. On the other hand, if the energy is too high the peak of measured implant profile will be very deep, $>800 \mathrm{~nm}$, resulting in an impractically long SIMS measurements. The depth of the implant peak can be chosen by modelling the implantation process for different ion energies 
by using the SRIM-2003 code (Ziegler, 2004). The energy of the implanted ion beam will be constrained by the energy limits of the implanting instrument. If the limit is too low doubly charged ions may be considered, however, the ion source brightness may be lower resulting in an excessively long implantation time.

Two considerations apply when choosing the desired fluence. Firstly, the peak of the implant should be at least an order of magnitude above the natural concentration of the element in the materials of interest. This is required in order to completely overprint the naturally abundance of the element of interest which may be heterogeneous and could otherwise disturb the implant measurement. This method will achieve the best results when applied to materials with very low abundances of the element of interest. Secondly, it is also important to independently calibrate the implant fluence because the ion implanting instruments have low mass resolution so minor interferences can affect the dose measured during the implant such that the nominal fluence can only be considered 10-20\% accurate (Heber et al., 2014; Burnett et al., 2015). The fluence of the implant can be calibrated by comparison with a standard of known concentration and ideally ought to exceed this concentration by a factor of 2 to 10 to enable good precision during SIMS analysis.

\subsection{Determining the implanted fluence}

Following the approach of Leta and Morrison (1980), consider two sputtered regions, $j$ and $k$, of the same mineral which have different, but homogeneous, concentrations of an element. As the concentrations are different, the measured count rates will be different. However, ratio of the count rate (I) over the concentration (C) will be equal.

$$
\frac{I_{j}}{C_{j}}=\frac{I_{k}}{C_{k}}
$$

If instead of a single homogeneous concentration, one of the regions were an implant, the concentration and resulting intensity would change continuously through the implant profile. The profile will grow to a maximum and then decay to the natural background level of the material. The integrated counts over an implant profile can be considered equivalent to the counts over a hypothetical region of constant concentration, $\mathrm{A}_{i}=\mathrm{A}_{h e}$ as seen in figure 1 . Therefore, these two regions may be compared as before in the homogeneous case, see figure 


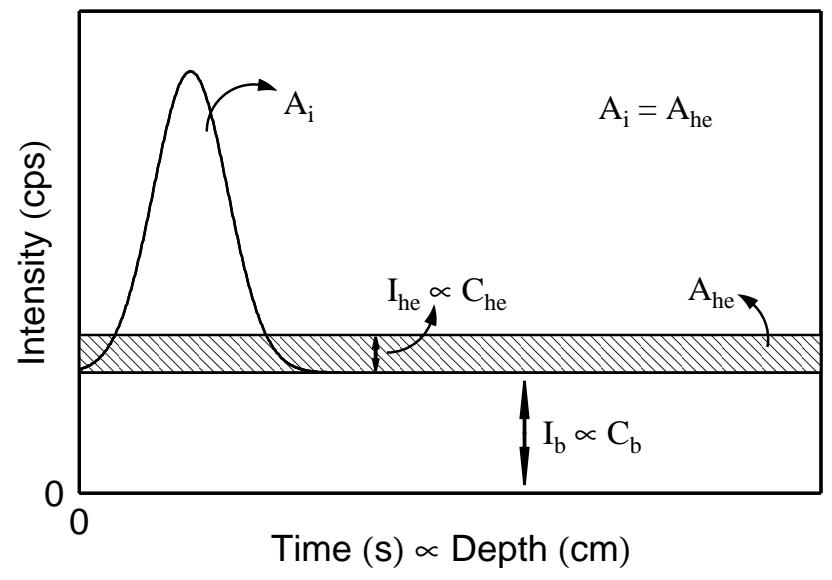

Figure 1: Schematic diagram of an implant profile in a glass with a known concentration of the element of interest. $\mathrm{I}_{b}$ is the intensity of the background, $\mathrm{C}_{b}$ is the concentration of the background, $\mathrm{A}_{i}$ is the integrated area of the implant profile, $\mathrm{A}_{h e}$ is a hypothetical region with the same area integrated implant profile, $\mathrm{I}_{h e}$ is the intensity of a hypothetical region with the same area as the implant profile, $\mathrm{C}_{h e}$ is the concentration of a hypothetical region with the same area as the implant profile.

1.

As the fluence of the implant $(\mathrm{F})$ is the number of atoms implanted per square $\mathrm{cm}$, the concentration of the hypothetical region, and so the implant, is equal to

$$
C_{\text {i or he }}=\frac{F}{D} \text {, }
$$

where $\mathrm{D}$ is the total depth of the analysis, and the intensity the hypothetical region will yield is given by

$$
I_{\text {i or he }}=\frac{A_{i}}{t} \text {, }
$$

where $t$ is the total time of the analysis. Substituting equations 3 and 4 into equation 2, and rearranging, the fluence of the implant can be determined by

$$
F=\frac{C_{b} D A_{i}}{I_{b} t}
$$

Note that if the daughter element has more than one isotope the concentration $\mathrm{C}_{b}$, or $\mathrm{I}_{b}$, must be normalised for its isotopic abundance. 
Once the implant fluence has been independently calibrated it is possible to determine the RSF of any material that was implanted during the same implanting session, and so with the same fluence, as the standard material.

\subsection{Determining the RSF of an unknown material}

The RSF of an unknown sample may be determined using the same principles. Taking equation 1 we can replace the term for the true concentration of the daughter $\left(\mathrm{C}_{d}\right)$ with equation 3 and the term for the count rate of the ion probe measurement $\left(\mathrm{I}_{d}\right)$ with equation 4 . After simplifying this yields

$$
\mathrm{RSF}=\frac{\mathrm{C}_{\mathrm{p}} \mathrm{DA}_{\mathrm{i}}}{\mathrm{I}_{\mathrm{p}} \mathrm{Ft}} .
$$

Note that if the parent element has more than one isotope the concentration $\mathrm{C}_{p}$, or $\mathrm{I}_{p}$, must be normalised for its isotopic abundance.

\subsection{Effects of implanting on crystal structure}

One of the concerns of using an ion implanting technique to investigate matrix effects is that the ion implanting itself may change the RSF for a given material. This may occur either by changing the composition or structure of the mineral. Firstly, assuming that the implant is deposited in the top $250 \mathrm{~nm}$ of the carbonate, the fluence that is used in our implantation experiments amounts to an addition of $\sim 50 \mathrm{ppm}$ averaged over the entire implant depth. Even if the entire fluence were deposited in only the top $50 \mathrm{~nm}$ the concentration would not exceed $250 \mathrm{ppm}$. Because this represents such a small change in the matrix, we can assume that any effect on the RSF from the implant due to alteration of the matrix composition is negligible.

A further concern could, in principle, be that the implantation process may alter the matrix effect of the minerals by disrupting the crystal structure. It is helpful here to illustrate just how low the intensity of the implanting ion beam is. During every second of the 30 - 60 minute ion probe analysis, under typical running conditions, the fluence of the primary beam is $\sim 30$ - 40 times higher than the total fluence of the implant. 


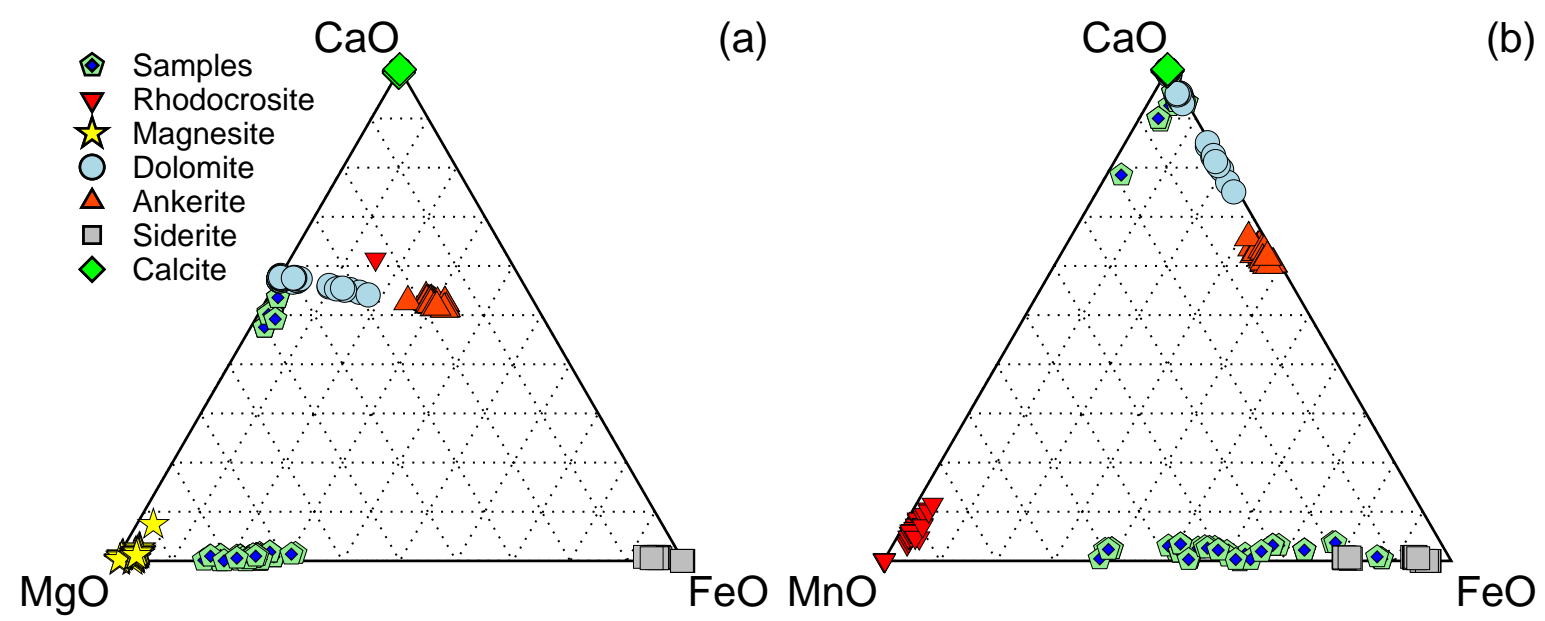

Figure 2: Ternary diagrams showing the compositions of the implanted carbonate standards and the range of eventual carbonate unknown samples from primitive meteorites.

\section{Methods}

\subsection{Samples and Standards}

The ultimate aim of this work is to investigate the variation in RSF of a range of carbonate minerals in order to determine the accuracy of $\mathrm{Mn} / \mathrm{Cr}$ ages of carbonates from primitive meteorites. The meteoritic samples have a wide range of compositions (Endress et al., 1996) covering dolomites $\left(\mathrm{CaMg}\left[\mathrm{CO}_{3}\right]_{2}\right)$ and breunnerites $\left([\mathrm{Mg}, \mathrm{Fe}] \mathrm{CO}_{3}\right)$, shown as green stars in fig 2 . We have chosen a suite of carbonate standards that span the entire compositional range of the major carbonates. Manganese-Cr data for two of these breunnerites from the CI chondrite Orgueil are reported below.

The end-member carbonate compositions which we implanted were calcite, dolomite, siderite, magnesite, rhodocrosite and ankerite, see fig. 2. We attempted to directly measure the breunnerite RSF, however, the breunnerite grains that were implanted were very small and due instrumental limitations in the size of the primary beam are not reported in this study. In addition, we implanted San Carlos olivine for comparison with the carbonates and the NIST standard glasses SRM 610, SRM 612 and SRM 614 for calibrating the implant fluence. 


\subsection{Ion implantation}

The standards were mounted in 1 inch diameter epoxy mounts. The mounts were polished for ion probe analysis by using $\mathrm{SiC}$ and diamond polishing cloths and finally $1 \mu \mathrm{m} \mathrm{Al}_{2} \mathrm{O}_{3}$. The standard mounts were then coated with $\sim 15 \mathrm{~nm}$ of carbon to avoid charging during ion implantation. These mounts were fixed on a Si wafer (10 cm in diameter) using carbon tape and graphite paint. Several Si wafer chips were fixed at the same height as carbonate and glass mounts spread over a larger area of the implant target. The Si wafer chips were subsequently examined to estimate the homogeneity of the implant as described below.

The Si wafer, with the carbonate and silicate standards and Si wafer chips attached, was then implanted with a $185 \mathrm{keV}{ }^{52} \mathrm{Cr}^{+}$ion beam. The beam was rastered over a $12 \times 12 \mathrm{~cm}$ grid exceeding the area of the wafer surface. Faraday cups located at the four corners of the rastered area monitored the implant dose and homogeneity. The nominal implanted fluence was $4 \times 10^{13} \mathrm{~cm}^{-2}$. The implanting was carried out by CuttingEdge Ions, Anaheim California.

\subsection{Secondary ion mass spectrometry}

Ion implanted standards were analysed using the CAMECA IMS 1270 at UCLA. Depth profiles were measured in both the NIST glasses, to calibrate the implant fluence, and the carbonates to determine the range of $\mathrm{Mn} / \mathrm{Cr} \mathrm{RSFs}$ according to the methods described above. After ion implantation the samples were gold coated and sputtered with a $22.5 \mathrm{keV} O$ primary ion beam. In order to minimise impact energy and therefore improve depth resolution, we investigated use of an $\mathrm{O}_{2}^{-}$primary ion beam. This primary beam yielded a $60 \%$ higher intensity $\left(\right.$ cps $\left.\cdot \mathrm{nA}^{-1}\right) \mathrm{Cr}^{+}$secondary ion beam than $\mathrm{O}^{-}$did under identical instrumental conditions and so was used for all analyses. Primary beam currents ranged from $\sim 2$ to $10 \mathrm{nA}$. The primary beam was tuned to a $\sim 20 \mu \mathrm{m}$ spot and was rastered over a $\sim 100 \mu \mathrm{m}$ by $\sim 100 \mu \mathrm{m}$ area of each implanted sample. A rectangular field aperture was inserted into an imaged field plane to restrict transmitted ions to the central 20 by $20 \mu \mathrm{m}$. The exact raster and field aperture size varied slightly between analytical sessions based on the conditions of the primary beam but the relative sizes were kept constant from one sample to another and between analytical sessions. Secondary ions were collected with both an electron multiplier (EM) for the implant profile and trace elements and Faraday cup (FC) for matrix elements. The EM and FC were inter-calibrated by measurement of a single ion beam tuned to $0.5 \times 10^{6} \mathrm{cps}$ and $1 \times 10^{6} \mathrm{cps}$. 

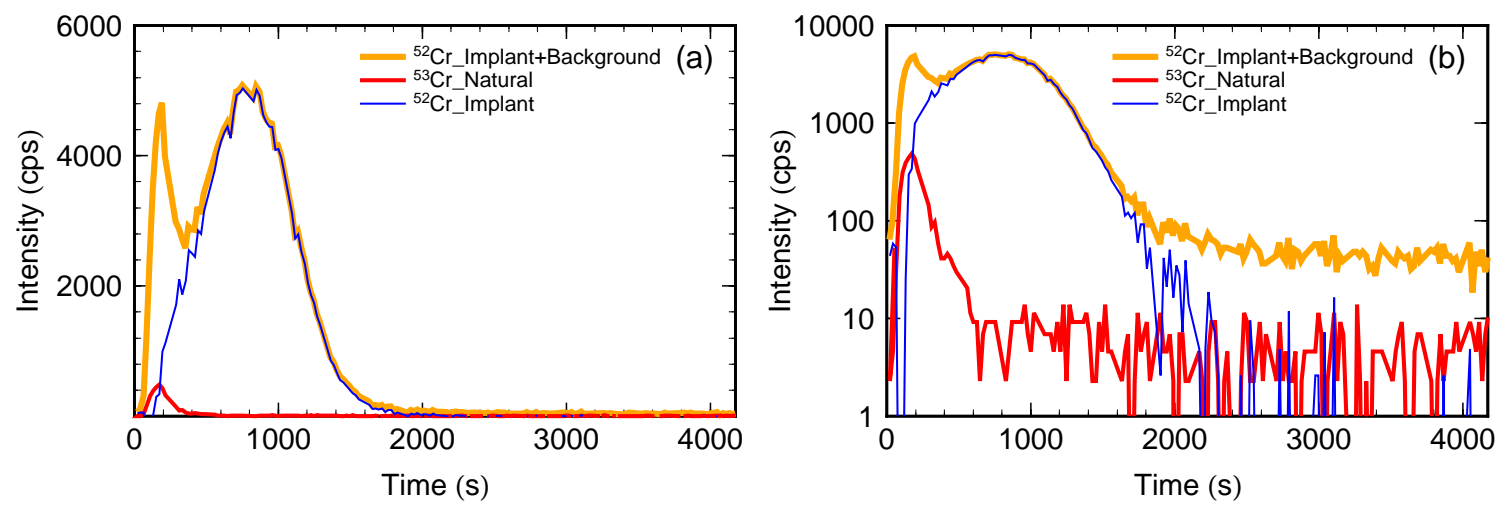

Figure 3: Plots showing a characteristic ${ }^{52} \mathrm{Cr}$ implant profile measured in an ankerite. The left panel is shows a linear scale to illustrate the true shape of the implant profile and the right panel shows a log scale to demonstrate that a stable background is reached. The initial $400 \mathrm{~s}$ of the depth profile are characterised by an enhanced Cr signal due to contamination from the surface of the mount 'gardened' in by the primary beam and nonequilibrium sputtering. These surface features can be removed by either peak stripping based on the measured surface contamination of ${ }^{53} \mathrm{Cror}$ by using a SRIM (Ziegler, 2004) to model correct the shape of the implant profile to replace the affected data. Experiments show that both techniques yield essentially identical results (much better than the reproducibility between measurements).

The deadtime correction of the EM was adjusted by the duty cycle of the raster which was determined by measuring the beam with the dynamic transfer lens of the instrument set to transmit the entire beam through the field aperture or only the analytical area or interest.

We examined the energy distributions of $\mathrm{Mn}$ and $\mathrm{Cr}$ and found there was no discernible offset between them. In order to minimise the chances of a difference in energy distribution inducing a matrix effect, a wide energy window of $50 \mathrm{eV}$ was set and sample charging was monitored every 10 measurement cycles ( $\sim-4$ minutes), adjusting the accelerating voltage as needed to keep the initial kinetic energy of transmitted secondary ions as constant as possible.

The samples and standards were sputtered through the peak of the profile until the signal had decayed and reached a stable background, see fig. 3. The time that this required varied significantly from session to session and mineral to mineral, ranging from 45 mins to 3 hours, though most depth profiles concluded within 1 to 1.5 hours.

Two breunnerite grains from the primitive carbonaceous chondrite Orgueil were analysed with almost identical analytical parameters. The most significant difference was the use of a spot rather than a raster, the implications of this for the instrumental RSF are discussed in 
section 5.3. Corrections for instrumental mass dependent fractionation in $\mathrm{Cr}$ isotopes were made by sample standard bracketing using San Carlos Olivine and NIST glasses 610 and 612. Potential for inaccuracy in the measured ratios resulting from statistical bias due to low denominator count rates (Ogliore et al., 2011; Coath et al., 2013) was examined. Correction using the ratio of sums method (Ogliore et al., 2011) and the method of (Coath et al., 2013) were found to yield identical result with error.

\subsection{Electron Microprobe Analysis}

Major element compositions of the carbonates and olivine were determined using the UCLA JEOL JXA-8200 Superprobe. Samples were analysed using a $15 \mathrm{kV}$ accelerating potential and $10 \mathrm{nA}$ beam defocused to a $10 \mu \mathrm{m}$ spot to limit sample damage. The measurement counting times were $20 \mathrm{~s}$ with a $5 \mathrm{~s}$ background measurement. An in house rhodocrosite standard was used for $\mathrm{MnO}$ and standards from the Smithsonian National Museum of Natural History were used for $\mathrm{Ca}$ (calcite), $\mathrm{Fe}$ (siderite) and $\mathrm{Mg}$ (dolomite). Standard ZAF corrections were used to obtain cation abundances and $\mathrm{CO}_{3}$ anion contents were calculated by difference.

\subsection{Depth Measurements}

It is important to accurately know the ion probe raster pit depths in order to determine either the fluence of the implant or the RSF of carbonates, see section 2 and equations 5 and 6. The depths were determined using a Bruker DektakXT stylus profilometer at the Molecular Materials Research Center, Caltech. The instrument has a vertical resolution of $0.1 \mathrm{~nm}$ and was calibrated with certified step height standards before and after every analytical session. Slight deviation from the certified values $(\sim 1 \%)$ was observed in the step height standard data. This deviation was never outside error of the certified values, however, it was consistently in the same direction for all step height standards which is extremely unlikely to occur due to chance. The deviation was corrected in the unknowns with a linear interpolation through the step height standard data. Based on a pooled dataset of every analysis of step height standards and unknown SIMS pits the external reproducibility is estimated to be $4.2 \%$ at 2 standard deviations (2 S.D.) for a single analysis. Unknowns were measured between 2 and 9 times. Depth measurements were also made by using a ADE Phase Shift MicroXAM Optical interferometer, however, for some samples this method proved unreliable due to the difference 
in reflectivity between the pit depth and the gold coated surface. No depth measurements determined using the MicroXAM were used for the RSF analyses reported here

\section{Results}

\subsection{Implant Fluence}

The NIST standard glass SRM 612 with a chromium concentration of $36.26 \pm 1.16 \mathrm{ppm}$ (Jochum et al., 2011) was used to calibrate the fluence of the implant (note in their paper Jochum et al. report uncertainty as the relative standard deviation in percent, here we have converted this into $2 \mathrm{SD}$ absolute error). This standard was chosen because it has the appropriate concentration relative to that of the implant; the peak of the implant is $\sim 10$ times higher than the background signal. This glass was measured six times under the conditions described above and yielded an average value of $4.31 \pm 0.09 \times 10^{13} \mathrm{~cm}^{-2}( \pm 2.1 \% 2$ standard errors (2 S.E.)) for the fluence. We estimate the overall uncertainty by summing in quadrature the analytical reproducibility with the contribution due to the uncertainty in the NIST glass concentration; the propagated errors yield a final uncertainty of $0.16 \times 10^{13}(3.8 \%)$. The calibrated value is approximately $10 \%$ higher than the nominal implanted fluence given by the ion implanter. This discrepancy is somewhat puzzling. Ion implanting offers significant challenges for accurate fluence determination, however, where errors occur it is typical for implanted fluences to be too low rather than too high. This is because an interference in the implanting ion beam will increase the apparent dose causing the integrated current to be reached too soon. A fluence that is too high suggests that either the currents measured by the Faraday cups were not calibrated accurately, or when the beam was rastered across the sample it did not fully enter the Faraday cups. Both of these would act to reduce the apparent dose, and so increase the time exposure to achieve the desired nominal fluence. Regardless of the reason for the discrepancy, the fluence of the implant has been independently calibrated by measurement of the SRM 612 NIST glass standard and so this can have no effect on the $\mathrm{Mn} / \mathrm{Cr}$ RSFs determined in this work. Moreover, the homogeneity of the implant was measured by examining the Si wafer chips and showed that the implant is homogeneous to within $1.8 \%$ across the entire implanted area, which is less than the analytical uncertainties on the fluence or RSF measurements. 


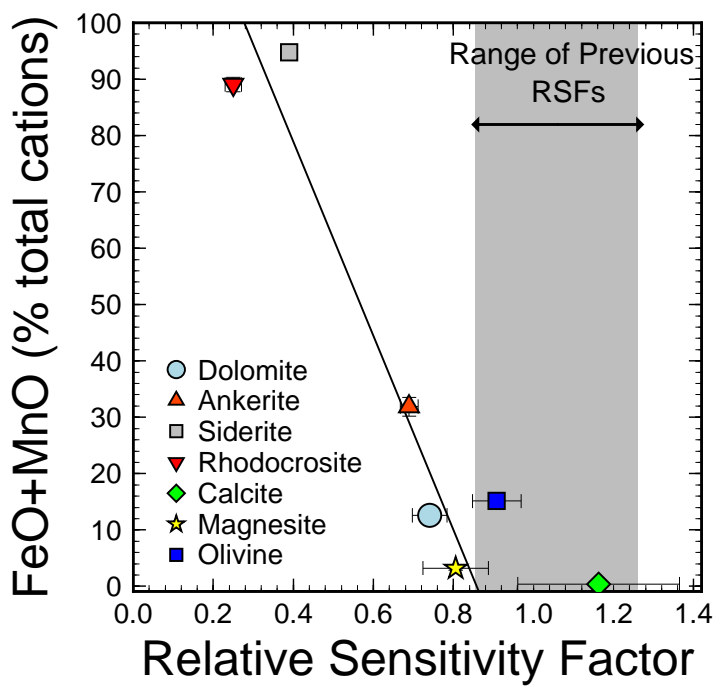

Figure 4: Plot showing the correlation between the $\mathrm{RSF}_{\mathrm{Mn} / \mathrm{Cr}}$ measured by ion implanting and the $\mathrm{FeO}+\mathrm{MnO}$ percentage of the carbonates. The line corresponds to a weighted regression through the carbonate points. Error bars are plotted for all points in both $\mathrm{x}$ and $\mathrm{y}$ but, in some cases, are smaller than the symbols.

\subsection{Variation in the $\mathrm{Mn} / \mathrm{Cr} \mathrm{RSF}$ in carbonates}

Our depth profiles reveal significant variation in the $\mathrm{Mn} / \mathrm{Cr} \mathrm{RSF}$ in the implanted carbonate standards, see table 1 and figure 4 . As can be seen in figure 4, these RSF results broadly correlate with the composition of the carbonates as indicated by the $\mathrm{FeO}+\mathrm{MnO}$ content. A similar, though positive, correlation is observed between $\mathrm{CaO}+\mathrm{MgO}$ vs. $\mathrm{RSF}$, though it is not clear to what extent this is simply due to the decreasing Fe and Mn concentrations (or vice versa). The measured $\mathrm{Mn} / \mathrm{Cr}$ RSFs extend considerably below 1 with the lowest value being found in the samples which have the highest concentrations of Fe and $\mathrm{Mn}$, the siderite and the rhodocrosite. The samples with intermediate concentrations of $\mathrm{Fe}$ and $\mathrm{Mn}$, for example dolomite and ankerite, show RSF values between $\sim 0.7$ and 0.8 , respectively. Calcite has the lowest concentration of $\mathrm{FeO}+\mathrm{MnO}$ and, somewhat surprisingly, has a $\mathrm{Mn} / \mathrm{Cr} \mathrm{RSF}$ greater than 1. The correlation of the RSF with composition is not perfect, and its range from $\sim 0.2$ to $\sim 1.2$ is large and denotes a very significant matrix effect. 


\begin{tabular}{|c|c|c|c|c|c|c|c|c|c|c|c|c|}
\hline & \multicolumn{2}{|c|}{ Measured } & \multicolumn{2}{|c|}{ Predicted } & \multirow[b]{2}{*}{$\mathrm{CaO}$} & \multirow[b]{2}{*}{$2 \mathrm{se}$} & \multirow[b]{2}{*}{$\mathrm{MgO}$} & \multirow[b]{2}{*}{2 se } & \multirow[b]{2}{*}{$\mathrm{MnO}$} & \multirow[b]{2}{*}{ 2se } & \multirow[b]{2}{*}{$\mathrm{FeO}$} & \multirow[b]{2}{*}{$2 \mathrm{se}$} \\
\hline & RSF & $2 \mathrm{se}$ & RSF & $2 \mathrm{se}$ & & & & & & & & \\
\hline $\mathrm{A}$ & 0.69 & 0.03 & 0.78 & 0.06 & 2 & 0.64 & 17.19 & 1.46 & .77 & 0.60 & 30.12 & 1.55 \\
\hline Cal & 1.16 & 0.20 & 1. & 0.14 & 99 & 0.19 & & & & 0. & & 0.17 \\
\hline Dol & 0.74 & 0.04 & 0.8 & 0.07 & 54.83 & 0.41 & & 0.34 & 68 & 0.13 & 11.92 & 0.45 \\
\hline Mag & 0.81 & 0.08 & & 0.05 & & 0.81 & & 1.00 & & 0.09 & & 0.37 \\
\hline $\mathrm{Ol}$ & & 0.0 & & 0. & & 0.0 & 84. & 0.26 & & 0.03 & 14.92 & 0.25 \\
\hline & & 0.0 & & 0.02 & & 1. & 2. & 0.13 & 86.40 & 1.28 & 2.64 & 0.20 \\
\hline Sid & 0.39 & 0.07 & 0.36 & 0.03 & 0.62 & 0.29 & 4.56 & 0.49 & 5.84 & 0.40 & 88.98 & 0.58 \\
\hline
\end{tabular}

Table 1: Table showing the measured and predicted RSF and compositions major elements (wt.\%) of a range of carbonates and San Carlos Olivine.

\subsection{Uncertainties on RSF measurements}

The reported $\mathrm{Mn} / \mathrm{Cr}$ RSFs are the product of several different measurements including: the depth profile of the ${ }^{52} \mathrm{Cr}$ implant fluence, the calibration of the implanted ${ }^{52} \mathrm{Cr}$, the depth measurement of the ion probe pit and the electron probe measurement of the Mn concentration. All of these measurements have associated uncertainties that must be propagated into the final RSF uncertainty. The external reproducibility of an RSF measurement has been estimated as $7 \%$ from a pooled dataset of repeat measurements of the ankerite, dolomite and siderite using a method described by Steele et al. (2011). This was summed in quadrature with the other measurement errors that contribute to the overall uncertainty. In this way an individual uncertainty for each measurement of an RSF was produced. The Mn/Cr RSF and analytical uncertainty for each carbonate and the olivine were then determined as the weighted mean of repeat measurements and its associated uncertainty. Finally these were combined with the error contribution from the fluence measurement to yield a final uncertainty including all contributions.

\subsection{Comparison to previous data}

There are two reasons for comparing our new RSF data with previously determined $\mathrm{Mn} / \mathrm{Cr}$ RSFs. Firstly, we want to assess the agreement of our study with previous work on similar materials. The second reason is that we have measured a wider range of samples than has 
previously been possible and our new data may have implications for previously published $\mathrm{Mn} / \mathrm{Cr}$ ages which we discuss below.

Only two of the minerals that we have measured, calcite and olivine, have been previously analysed in other studies. The most widely studied mineral is olivine; many investigators have used San Carlos olivine when determining a Mn/Cr RSF. In a recent study, McKibbin et al. (2013b) have shown the true complexity of this endeavour by demonstrating that there is significant variation in the RSF of olivine depending on composition along the $\mathrm{Mg}$-Fe solid solution. Interestingly, in common with this study, McKibbin et al. (2013b) also observe a relationship between the Mn/Cr RSF and the Fe concentration. Previously reported values for the Mn/Cr RSF of San Carlos olivine are summarised in figure 5. As can be seen in this figure there is significant variation outside of analytical error.

Two of the data, at the high and low extreme values, may not be directly comparable with the remaining majority of the data. The majority of the instruments used were variations of the

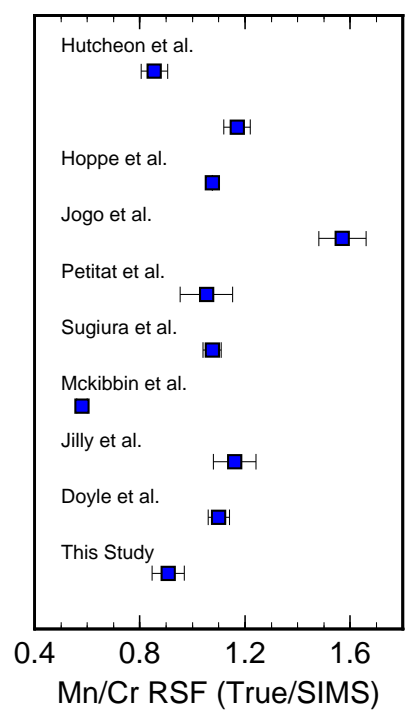

Figure 5: Figure summarising literature data for the Mn/Cr RSF of San Carlos olivine. Data from Hutcheon et al. (1998); Hoppe et al. (2007); Jogo et al. (2009); Petitat et al. (2009); Sugiura et al. (2010); McKibbin et al. (2013b); Jilly et al. (2014); Doyle et al. (2016). Note Hoppe et al. (2007) did not give an uncertainty on their RSF and Hutcheon et al. (1998) did not state if they used the measured/true or true/measured definition of the RSF so both are plotted. 
CAMECA ion probe. However, the data reported by McKibbin et al. (2013b) were collected with the SHRIMP-RG, which has somewhat different impact geometry and transmission characteristics to the CAMECA instruments. In addition, the highest RSF is that reported by Jogo et al. (2009) who analysed high energy ions (offset voltage of $100 \mathrm{~V}$ ), whereas the rest of the data represent only measurements of secondary ions sputtered with low initial kinetic energies.

Even excluding these extreme data, which represent distinct analytical conditions, there still exists significant variation $(\sim 30 \%)$ outside analytical uncertainties. This could be explained as being due to the range of different instruments and specific analytical conditions used among the various studies. On average, San Carlos olivine, when analysed with a forward geometry CAMECA ion probe with minimal energy filtering, yields an RSF of around 1. The RSF we measure for San Carlos olivine $(0.91 \pm 0.06)$ is on the lower side of those reported in the literature, however, small differences might be expected between instruments. The range of RSFs values in carbonates is therefore striking since these were measured by one technique, on one instrument, under the same analytical conditions.

The other mineral that has been previously studied by multiple laboratories is calcite. The calcite grown by Sugiura et al. (2010) has also been measured by Jilly et al. (2014). While Sugiura et al. (2010) investigated the Mn/Cr RSF using the CAMECA NanoSIMS, Jilly et al. (2014) used a CAMECA ims 1280, a similar instrument to the one used in this study. The two studies yielded similar results $1.27 \pm 0.08$ (Sugiura et al., 2010) and $1.42 \pm 0.36$ (Jilly et al., 2014). It must be noted that Jilly et al. (2014) measured profiles across the calcite using an electron probe and found the $\mathrm{Mn}$ and $\mathrm{Cr}$ concentration to be higher in the centre. Though the measured $\mathrm{Mn} / \mathrm{Cr}$ ratio did not show the same trend, both the $\mathrm{Mn} / \mathrm{Cr}$ ratio and the $\mathrm{RSF}$ varied outside analytical uncertainties. The error reported by Jilly et al. (2014) is the standard deviation of this variation. The calcite Mn/Cr RSF determined by Jilly et al. (2014) and Sugiura et al. (2010) is within error of the value determined by our ion implantation method, $1.16 \pm 0.20$. Thus, our results for the Mn/Cr RSF for the two minerals (San Carlos olivine and calcite) which have been previously reported are broadly consistent with literature values.

The second reason to compare our results with previous data is to see if our new results are within the range of RSFs previously applied to carbonates. The range of RSFs previously 
used for correcting the $\mathrm{Mn} / \mathrm{Cr}$ matrix effect in carbonates is shown by the grey area in figure 4. Almost all of our data fall outside the range of previously used RSFs, though of course we have measured the RSF of a much larger range of carbonate minerals than previous studies. This range in RSFs has significant implications for the $\mathrm{Mn} / \mathrm{Cr}$ ages obtained by these studies, see section 5.5 below for a discussion.

\section{5. $\mathrm{Mn} / \mathrm{Cr}$ data for Meteoritic Carbonates}

To illustrate the process and the effect of the correction we present $\mathrm{Mn} / \mathrm{Cr}$ ages for two breunnerites from the primitive carbonaceous chondritic meteorite Orgueil, see table 2 and figure 6. The data were collected under identical analytical conditions to the depth profiles with the exception that a raster was not used (due to the small grain size). The data have been corrected for the matrix effect by using the olivine RSF of $0.78 \pm 0.06$ and RSFs estimated from equation 7, $0.55 \pm 0.08$ for Breun-33 and $0.60 \pm 0.04$ for Breun-25, see section 5.2. As can be seen from figure 6 there is a significant change in the slope of the isochron. The data for Breun-25 are shifted from an age $6.6_{-1.0}^{+1.2} \mathrm{Ma}$ after CAI based on the olivine RSF to 3.5 ${ }_{-1.0}^{+1.2}$ Ma corrected using the breunnerite RSF. Though the 2 standard deviation (s.d.) errors overlap, largely due to the significant analytical uncertainty for $\mathrm{Mn} / \mathrm{Cr}$ measurement of this carbonate, this represents a shift of $>2 \sigma$. The data for Breun-33 are more precise and yield a better resolved shift. Using the olivine RSF the data yield $3.6_{-0.5}^{+0.5} \mathrm{Ma}$ after formation of CAIs, whereas with the breunnerite RSF calculated using equation 7 the data yield an age of $1.8_{-0.4}^{+0.5} \mathrm{Ma}$. Due to the more precise isochron, primarily due to the large range in $\mathrm{Mn} / \mathrm{Cr}$ ratio, this produces a well-resolved change of $>4.6 \sigma$. These ages, and those in figure 9 , are anchored to the D'Orbigney angrite by ${ }^{207} \mathrm{~Pb}^{206} \mathrm{~Pb}$ age $4563.37 \pm 0.25 \mathrm{Ma}$ from Brennecka and Wadhwa (2012) and the Mn/Cr data from McKibbin et al. (2015) that yield $\left({ }^{53} \mathrm{Mn} /{ }^{55} \mathrm{Mn}\right)_{0}$ $=3.54 \pm 018 \times 10^{-6}$. Importantly, Brennecka and Wadhwa (2012) directly measured the U isotope composition of D'Orbigney and so the $\mathrm{Pb}-\mathrm{Pb}$ age for D'Orbigney has been corrected for $\mathrm{U}$ isotope fractionation. The age of calcium, aluminium rich inclusion (CAI) formation was estimated from the two studies which have published $\mathrm{U}$-corrected $\mathrm{Pb}-\mathrm{Pb}$ ages of $\mathrm{CAI}$ (Amelin et al., 2010; Connelly et al., 2012) as $4567.30 \pm 0.16$ (Connelly et al., 2012). Implicit in this anchoring process is an estimate of the $\left({ }^{53} \mathrm{Mn} /{ }^{55} \mathrm{Mn}\right)_{0}$ of the Solar System which yields $7.4 \times 10^{-6}$ which is within the range of recent previous estimates $\left(6.28 \times 10^{-6}\right.$ to $9.1 \times 10^{-6}$ 
Trinquier et al., 2008; Nyquist et al., 2009, respectively). The implications of these data for early Solar System chronology and aqueous alteration on the CI parent body are discussed below, see section 5.5.

Also included in table 2 are $1 /{ }^{52} \mathrm{Cr}$ data. These may be used to examine to what extent the correlations are controlled by variation in $\mathrm{Mn}$ or $\mathrm{Cr}$ concentration. In both cases the correlation between ${ }^{53} \mathrm{Cr} /{ }^{52} \mathrm{Cr}$ and ${ }^{55} \mathrm{Mn} /{ }^{52} \mathrm{Cr}$ is better than the correlation between ${ }^{53} \mathrm{Cr} /{ }^{52} \mathrm{Cr}$ and $1 /{ }^{52} \mathrm{Cr}$ (Breun-25 MSWD = 1.42 and 5.28 while Breun-33 MSWD = 2.90 and 4.83). It is clear, however, that the $\mathrm{Cr}$ concentration plays the dominant role in controlling the variation of the ${ }^{55} \mathrm{Mn} /{ }^{52} \mathrm{Cr}$, but this is not unexpected. Manganese is a matrix element in breunerite and so is relatively homogeneous in concentration. Chromium on the other hand is excluded from the crystal structure and known to by highly heterogeneous (Hoppe et al., 2007). Therefore, the variation in the ${ }^{55} \mathrm{Mn} /{ }^{52} \mathrm{Cr}$ is controlled primarily by regions with anomalously high $\mathrm{Cr}$. It must be remembered that this in no way precludes in situ decay, it simply does not prove that the correlations are not mixing lines.

\begin{tabular}{lrrrrrrrrrr}
\hline \hline Sample & $\begin{array}{r}{ }^{55} \mathrm{Mn} /{ }^{52} \mathrm{Cr} \\
\text { Ol RSF }\end{array}$ & 2 se & $\begin{array}{r}{ }^{55} \mathrm{Mn} /{ }^{52} \mathrm{Cr} \\
\mathrm{Carb} \text { RSF }\end{array}$ & $2 \mathrm{se}$ & ${ }^{53} \mathrm{Cr} /{ }^{52} \mathrm{Cr}$ & $2 \mathrm{se}$ & $\rho$ & $1 /{ }^{52} \mathrm{Cr}$ & $2 \mathrm{se}$ \\
\hline Breun-25-1 & 1120 & 88 & 736 & 56 & 0.11342 & 0.00100 & -0.07 & $1.32 \times 10^{-5}$ & $8.71 \times 10^{-7}$ \\
Breun-25-2 & 1013 & 80 & 666 & 51 & 0.11402 & 0.00100 & 0.08 & $1.34 \times 10^{-4}$ & $1.05 \times 10^{-5}$ \\
Breun-25-3 & 1543 & 121 & 1014 & 77 & 0.11522 & 0.00102 & 0.28 & $2.01 \times 10^{-4}$ & $1.00 \times 10^{-5}$ \\
Breun-25-4 & 1320 & 103 & 868 & 66 & 0.11361 & 0.00100 & -0.27 & $1.43 \times 10^{-4}$ & $4.08 \times 10^{-6}$ \\
Breun-25-5 & 1922 & 151 & 1264 & 96 & 0.11490 & 0.00101 & -0.04 & $2.14 \times 10^{-4}$ & $6.22 \times 10^{-6}$ \\
Breun-25-6 & 2072 & 171 & 1362 & 109 & 0.11673 & 0.00103 & 0.42 & $2.19 \times 10^{-4}$ & $1.41 \times 10^{-5}$ \\
Breun-25-7 & 4511 & 354 & 2966 & 226 & 0.12010 & 0.00119 & 0.27 & $4.85 \times 10^{-4}$ & $2.10 \times 10^{-5}$ \\
Breun-25-8 & 1531 & 120 & 1006 & 77 & 0.11437 & 0.00101 & 0.46 & $1.74 \times 10^{-4}$ & $8.02 \times 10^{-6}$ \\
Breun-25-9 & 1343 & 105 & 883 & 67 & 0.11377 & 0.00100 & 0.12 & $2.85 \times 10^{-4}$ & $5.52 \times 10^{-6}$ \\
Breun-25-10 & 2230 & 305 & 1466 & 198 & 0.11647 & 0.00413 & 0.27 & $3.36 \times 10^{-4}$ & $3.94 \times 10^{-5}$ \\
\hline Breun-33-1 & 22530 & 7589 & 13561 & 4568 & 0.18343 & 0.01900 & 0.96 & $1.36 \times 10^{-3}$ & $4.17 \times 10^{-4}$ \\
Breun-33-2 & 461 & 121 & 278 & 73 & 0.11388 & 0.00811 & 0.30 & $3.26 \times 10^{-5}$ & $8.09 \times 10^{-6}$ \\
Breun-33-3 & 68218 & 16717 & 41061 & 10062 & 0.35767 & 0.02546 & 0.93 & $2.78 \times 10^{-3}$ & $1.49 \times 10^{-4}$ \\
Breun-33-4 & 52195 & 12791 & 31416 & 7699 & 0.26946 & 0.03132 & 0.99 & $2.26 \times 10^{-3}$ & $3.82 \times 10^{-4}$ \\
\hline
\end{tabular}

Table 2: $\mathrm{Mn} / \mathrm{Cr}$ data for breunnerites from Orgueil. The data are presented corrected for the $\mathrm{Mn} / \mathrm{Cr}$ matrix effect using an RSF from olivine and one estimated for the breunnerite composition based on equation 7 . Uncertainties from the RSF correction have been propagated into the uncertainties from the measurement. Also shown is the correlation coefficient $(\rho)$ between the errors in ${ }^{55} \mathrm{Mn} /{ }^{52} \mathrm{Cr}$ and ${ }^{53} \mathrm{Cr} /{ }^{52} \mathrm{Cr}$. Errors are $2 \sigma$ and represent the internal error or the external error, whichever is larger. 

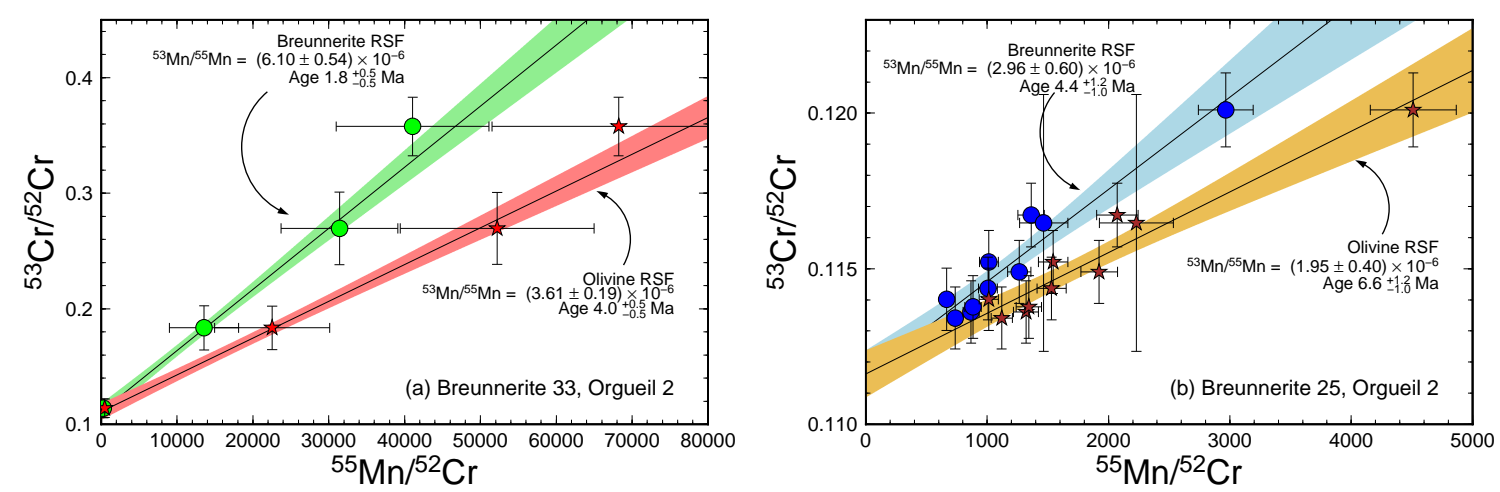

Figure 6: $\mathrm{Mn} / \mathrm{Cr}$ data for breunnerites from Orgueil. The data are presented corrected for the $\mathrm{Mn} / \mathrm{Cr}$ matrix effect using an RSF from olivine (stars) and one estimated for the breunnerite composition based on equation 7 (circles). The data corrected for the Mn/Cr matrix effect using the breunnerite RSF yield older ages by 2-3 Ma.

\section{Discussion}

\subsection{Variation in $R S F$}

We observe a systematic and large variation in the $\mathrm{Mn} / \mathrm{Cr} \mathrm{RSF}$ of carbonates from $\sim 0.2$ for rhodocrosite to 1.2 for calcite. This is reminiscent of the range in $\mathrm{Mn} / \mathrm{Cr} \mathrm{RSF}$ found in olivine by McKibbin et al. (2013b), although larger by a factor of 2. As noted by McKibbin et al. (2013b), and supported by all the olivine data summarised above, when similar analytical conditions are used, minerals of similar chemical composition have $\mathrm{Mn} / \mathrm{Cr}$ RSFs that are comparable, even if measured on different instruments. All data in this study were taken on the same instrument using similar conditions, however, we did conduct a series of tests to investigate the effects of varying analytical conditions on the Mn/Cr RSF values. Tuning to higher mass-resolving power and employing oxygen flooding yielded essentially no variation in measured $\mathrm{Mn} / \mathrm{Cr}$ RSFs. We conclude that the most likely explanation for the variation in measured $\mathrm{Mn} / \mathrm{Cr} \mathrm{RSF}$ is due to differences in the surface chemistry of each sample occurring during the sputtering process. This conclusion is supported by the correlation between the measured RSF and the chemical composition of the carbonate minerals (figure 4). Though it is not clear exactly what chemical processes, or characteristics, are controlling the change in RSF, the involvement of Fe suggests it could be related to the conductivity of the minerals. In support of this hypothesis we note a correlation between the resistivity (the reciprocal of 


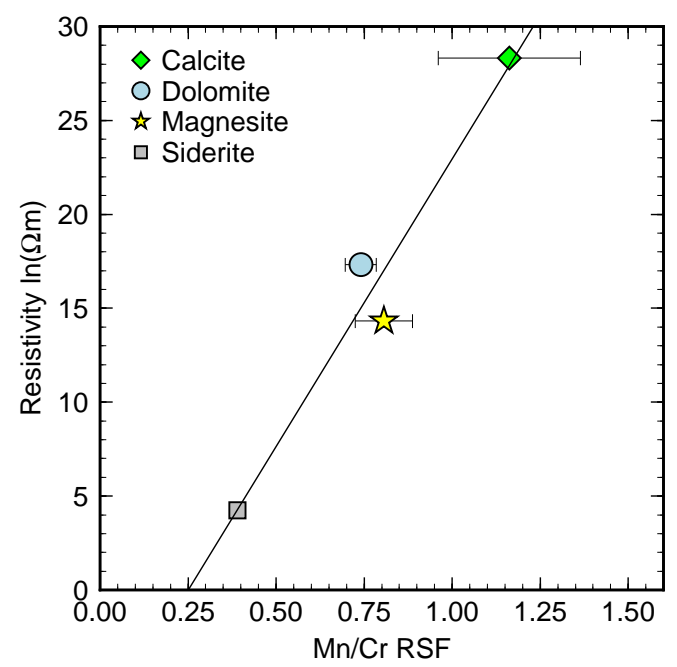

Figure 7: Plot showing the relationship between the resistivity of minerals and the measured Mn/Cr RSF. Resistivity data taken from Telford and Sheriff (1990); Papathanassiou (1998); Papathanassiou and Grammatikakis (1996)

conductivity) and the measured Mn/Cr RSF (figure 7). Although intriguing, this relationship is difficult to investigate further due to the lack of published resistivity data for the full range of minerals for which $\mathrm{Mn} / \mathrm{Cr}$ RSF values have been measured.

The correlation with resistivity potentially raises a concern that our results were somehow perturbed by the minerals with higher resistivity (e.g. calcite) charging more during ion implantation and, thus, receiving a lower implant dose than more conductive minerals (e.g. siderite). However, this goes counter to the observations and is unlikely for several reasons. Firstly, we note that our measured RSF for calcite is within error of those previously determined by other studies (e.g. Sugiura et al., 2010; Jilly et al., 2014), strongly suggesting that they received the same fluence as the standard glass. Secondly, the samples and standards were carefully carbon coated and each mount was grounded with carbon tape and paint to the Si wafer in order to minimise charging. Finally, if the fluence used to determine the RSF (as calibrated in the glass) was lower than the actual implanted fluence, as would be the case for a more conductive mineral, this would lead to an erroneously high RSF (equation 6). For these reasons we are confident that the calibrated fluence is appropriate for all implanted standards. 


\subsection{Predicting the appropriate $R S F$ for an unknown carbonate}

We conclude that the variations we observe in RSF are due to a systematic matrix effect with mineral chemistry. This means is should be possible to find a method to correct for variations in mineral matrix so as to predict the appropriate RSF to use for a given carbonate sample. This will avoid having to directly determine the RSF on a standard of exactly the same composition, which in many cases is not available. Our purely empirical approach has the advantage that the composition of a carbonate mineral may be easily and accurately determined by electron probe. While the relationship we observe between the measured RSF and the $\mathrm{Fe}+\mathrm{Mn}$ concentration is significant, the correlation is not perfect. Therefore, we sought a better way to accurately predict the $\mathrm{Mn} / \mathrm{Cr} \mathrm{RSF}$ for the full range of carbonate compositions.

One method to improve the empirical correlation between the RSF and the proxy for matrix is to vary the coefficients which describe the weighting of the chemical components. Simply adding the concentrations of $\mathrm{Mn}$ and Fe weights them equally. We used the linear model fitting package $\mathrm{lm}$ of the $\mathrm{R}$ statistical programming language (R Core Team, 2013; Chambers, 1992; Wilkinson and Rogers, 1973) to examine the effects of varying the weights on the different matrix elements in carbonates on the correlation with measured RSF. We used the stepAIC function of the MASS package (Venables and Ripley, 2002) to assess the

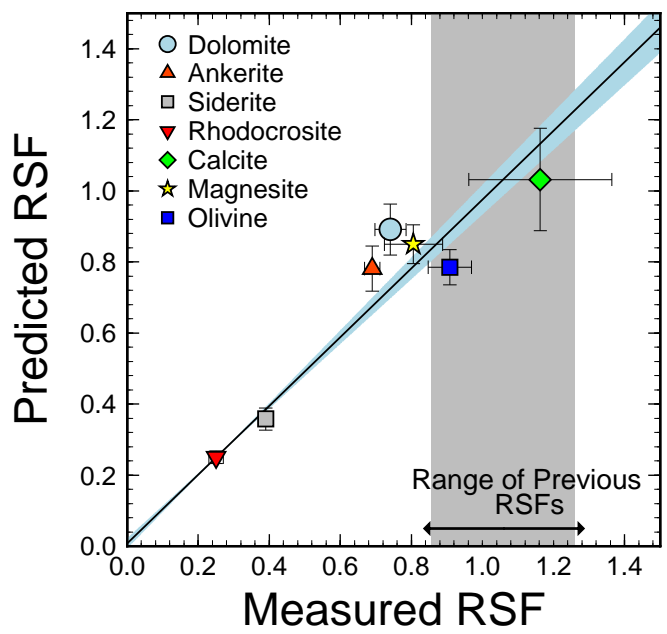

Figure 8: Figure showing the correlation of the measured RSF versus the predicted RSF from equation 7 . These data show good correlation close to unity with a slope of $0.97 \pm 0.06$. 
improvements, or lack of improvement, of each addition to the system. The results of this

process yield,

$$
\text { Predicted RSF }=-0.0017 \cdot[\mathrm{MgO}]+-0.0088 \cdot[\mathrm{MnO}]+-0.0069 \cdot[\mathrm{FeO}]+1.0349 \text {. }
$$

After finding the combination which gave the best fit, a Monte Carlo simulation was made to estimate the uncertainty on the predicted RSF using the new weights. These predicted RSFs and their uncertainties are given in table 1 . The same process may be used to estimate the RSF of an unknown based on the $\mathrm{MgO}, \mathrm{MnO}$ and $\mathrm{FeO}$ concentrations and their uncertainties.

\subsection{RSF Future Directions}

We now turn to two questions regarding application of the empirical calibration that we have found in this experiment: (1) what future SIMS studies are needed to test how robust are the $\mathrm{Mn} / \mathrm{Cr}$ matrix effects? and (2) is it possible to correct previous $\mathrm{Mn} / \mathrm{Cr}$ data for matrix effects. Regarding the first, the best approach would be to repeat the method we have described here with a variety of SIMS instruments to investigate how consistent the matrix effect shifts are in carbonates measured by different instruments and under different tuning conditions. We would be interested in collaborating on such projects and can provide implanted samples. A key question is whether the relative matrix effect we observe between two carbonates is constant, even if absolute RSF values are shifted, when using a different instrument or analytical setups.

Based on the currently available data, this seems to be the case. For example, Doyle et al. (2016) investigated the effects of different tuning parameters, such as spot size and primary beam intensity, on the RSF in olivine. They found that there was a small effect on RSF induced by different tuning parameters but that the dominant control on variation in RSFs was differences in mineral chemistry. Moreover, two recent studies have determined the RSF of calcite; using a rastered beam, Sugiura et al. (2010) found an RSF $=1.26 \pm 0.08$, whereas using a spot analysis, Jilly et al. (2014) found an RSF $=1.41 \pm 0.26$. Importantly, these are within error of each other, and of our estimate (1.16 \pm 0.20$)$, suggesting that differences between spot and raster mode analyses are of secondary importance. Doyle et. al also concluded that the 
relative changes in RSF between different mineral compositions were constant but that they may be shifted by a small amount in an absolute sense by tuning conditions.

Having said this, the variation in RSF observed in San Carlos by different studies across a wide variety of instruments is small by comparison to the matrix effects observed between carbonates. This suggests that while the RSFs we have measured are likely not absolute, they may accurately describe relative variation in the matrix effect between different carbonates. Therefore, the relationship we describe in RSFs may be applied to other studies by normalising the relative deviation to a common sample, e.g., the widely available San Carlos olivine, to adjust the relative variation to the absolute matrix effect of each individual instrument and set of tuning conditions. Future studies can use the relationship we describe here to estimate the RSF of unknowns.

For comparison with literature data an isochron may be corrected directly since any change in the $\mathrm{Mn} / \mathrm{Cr}$ ratio, caused by changes in the RSF, will have a proportional effect on the slope. For example, if the $\mathrm{Mn} / \mathrm{Cr}$ ratio is halved by a change in the RSF the slope of the isochron will become steeper by a factor of two. We can correct literature data for the variation we observe between different carbonate minerals using the relation

$$
\left({ }^{53} \mathrm{Mn} /{ }^{55} \mathrm{Mn}\right)_{\text {corrected }}=\left({ }^{53} \mathrm{Mn} /{ }^{55} \mathrm{Mn}\right)_{\text {original }} \times \frac{\mathrm{RSF}_{\text {origina material }}}{\mathrm{RSF}_{\text {true material }}} .
$$

For example, if the original study determined an RSF using olivine and reported data for a dolomite, the slope should be multiplied by $0.78 / 0.74=1.05$, resulting in a $5 \%$ steeper isochron. The resulting ages will only be an estimate of the true ages since there may be subtle variations between instrument and tuning conditions, however, it is likely the general variation in RSF between different minerals will remain.

\subsection{Outstanding Problems with the Mn/Cr System}

By accurately correcting the matrix effect more accurate relative ages may be achieved for different carbonate minerals. However, the accuracy of absolute $\mathrm{Mn} / \mathrm{Cr}$ ages is also reliant on the accuracy and precision of several other measurements. Firstly, there are uncertainties associated with the anchoring of the relative $\mathrm{Mn}-\mathrm{Cr}$ system to an absolute chronometer. This is normally achieved using a precisely determined ${ }^{207} \mathrm{~Pb}-{ }^{206} \mathrm{~Pb}$ age for an angrite for which the 
$\mathrm{Mn}-\mathrm{Cr}$ age has also been determined.

Another consideration is the accuracy of the ${ }^{53} \mathrm{Mn}$ half-life. Several recent studies have significantly revised the half-lives of two important early Solar System short-lived radionuclide, ${ }^{60} \mathrm{Fe}$ (1.5 (Kutschera et al., 1984) to $2.6 \mathrm{Ma}$ (Rugel et al., 2009)) and ${ }^{146} \mathrm{Sm}(103 \mathrm{Ma}$ (Friedman et al., 1966; Meissner et al., 1987) to $68 \mathrm{Ma}$ (Kinoshita et al., 2012). A more recent measurement of the ${ }^{53} \mathrm{Mn}$ half-life placed it a $3.00 \pm 0.15 \mathrm{Ma}$ (Yoneda et al., 2002) which is shorter than the previous estimate of $3.7 \pm 0.37$ (Honda and Imamura, 1971). These changes highlight the need to reassess these important natural constants.

\subsection{Implications for early Solar System chronology and parent body processes}

The finding of a large matrix effect on the $\mathrm{Mn} / \mathrm{Cr} \mathrm{RSF}$ of carbonates has implications for early Solar System chronology and the aqueous alteration history of Solar System bodies. We have demonstrated this with our new data for two breunnerite grains from the CI Orgueil accurate correction for the $\mathrm{Mn} / \mathrm{Cr}$ matrix effect shifts the formation ages of two breunnerite grains from the CI chondrite Orgueil to significantly earlier times. To illustrate the potential significance of accurately correcting for the matrix effect, we consider previously published $\mathrm{Mn} / \mathrm{Cr}$ data that used RSF values determined from silicate and carbonate minerals and adjust those data according to equation 8. Depending on the carbonate mineral, and the material used in the original study for matrix correction (usually San Carlos olivine), relative ages may get older, younger or stay the same (figure 9). Clearly, these data are only schematic and not a substitute for new data which accurately correct for the matrix effect under given analytical conditions. However, they demonstrate the likely shifts in the carbonate formation ages due to the matrix effect and may present a more reliable overall picture of secondary carbonate formation on meteorite parent asteroids than the scenarios that were previously based on incorrect RSF values.

There are several interesting features of the corrected data (figure 9) which may offer solutions to previous problems. Firstly, the spread of carbonate formation ages is significantly reduced, from $\sim 9 \mathrm{Ma}$ to $\sim 5 \mathrm{Ma}$ and the ages are significantly closer to the start of the Solar System (formation of CAIs). These earlier ages are more compatible with formation by aqueous alteration with fluids produced from heating by ${ }^{26} \mathrm{Al}$ on a small parent body. Secondly, the distribution of formation ages of dolomite and breunnerite grains overlap significantly 

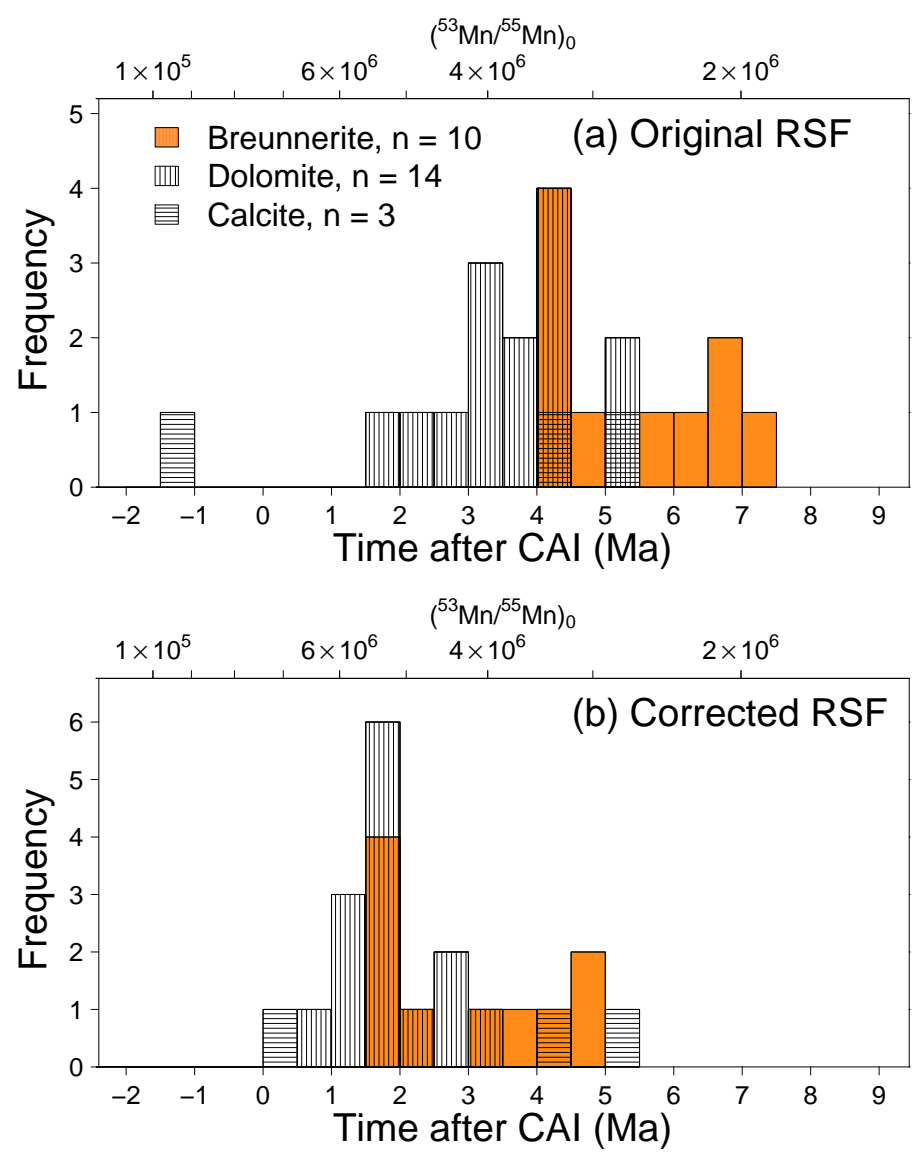

Figure 9: Figure showing $\mathrm{Mn} / \mathrm{Cr}$ ages after $\mathrm{CAI}$ for meteoritic carbonates from the literature (Hutcheon and Phinney, 1996; Hoppe et al., 2007; Petitat et al., 2009; Hutcheon et al., 1999; Fujiya et al., 2013; Petitat et al., 2011; Jilly et al., 2014; Fujiya et al., 2012, and this study). The data are presented as originally reported (a) and corrected for the observed variation in $\mathrm{Mn} / \mathrm{Cr}$ matrix effect using equation 8. Data for dolomites and breunnerites are shifted to early ages whereas calcite yield younger ages.

whereas previously, when matrix effects between these carbonates were not understood, it appeared that there was a gap or lull in carbonate formation between the early dolomite and later breunnerite populations (Petitat et al., 2009). The implications of carbonate formation for the timescales of accretion of carbonaceous chondrite parent bodies were examined by Fujiya et al. (2012, 2013). Based on their models, the revised narrower range of carbonate formation ages suggests either lower water ice content or smaller asteroidal radii of $\sim 30 \mathrm{~km}$ for the meteorite parent bodies. The size constraint of the body on which the carbonates formed may 
be relaxed somewhat if the body incorporated lower amounts of ${ }^{26} \mathrm{Al}$ due to heterogeneous ${ }^{26} \mathrm{Al} /{ }^{27} \mathrm{Al}$.

\section{Conclusions}

We used ion implantation to quantify the SIMS matrix effects on the Mn/Cr RSF in carbonate of varying composition. Measured RSFs can be determined by an empirical calibration with carbonate major element chemistry. This correlation may be used to predict the RSF of unknown samples thereby removing the need to directly measure the RSF in every sample of interest. The relationship we describe in equation 7 may be used to estimate the RSF of unknowns in other studies when adjusted by normalisation to a common sample, e.g. San Carlos olivine.

The RSFs predicted for dolomite and breunnerite are less than 1, and fall outside the range previously used for correcting the measured $\mathrm{Mn} / \mathrm{Cr}$ ratios. This suggests that the $\mathrm{Mn} / \mathrm{Cr}$ ages previously determined for meteoritic dolomites and breunnerites are likely not accurate and should be adjusted by 3-5 Ma to older ages, while the formation ages of meteoritic calcite may move to younger ages by $\sim 2 \mathrm{Ma}$. Of course new measurements are required which accurately correcting for the $\mathrm{Mn} / \mathrm{Cr} \mathrm{RSF}$ in a specific instrument under constant analytical conditions. Because the adjustment is greater for breunnerite than dolomite, previous suggestions of a gap in formation times require reconsideration. The shifts in the carbonate ages that are suggested by corrections for the matrix effect that we document here, makes it more likely that short-lived ${ }^{26} \mathrm{Al}$ can serve as the primary heat source for early aqueous alteration events that precipitated carbonates on the parent asteroids of CI and CR carbonaceous chondrites.

\section{Acknowledgments}

The authors thank Frank Kyte for help with electron probe analyses. We also thank the Molecular Materials Research Centre, Beckman Institute Caltech and Bruce S. Brunschwig for the use of their Dektak XT stylus profilometer and Fan Yang for his help during training. In addition, we acknowledge Michael Kroko and Brian Doherty of CuttingEdge Ions for their assistance with ion implanting. We greatly appreciate detailed reviews by two anonymous reviewers and careful editorial handling by Trevor Ireland, all of which helped to significantly 
improve the manuscript. We dedicate this paper to the memory of Ian Hutcheon, a great scientist, mentor, and friend who made many fundamental contributions to our understanding of early solar system chronology through SIMS measurements of short-lived radionuclide systems, including ${ }^{53} \mathrm{Mn}$. This work was funded by the NASA Laboratory Analysis of Returned Samples program; the UCLA ims-1270 ion microprobe laboratory is partially supported by a grant from the NSF Instrumentation and Facilities Program.

Amelin, Y., Kaltenbach, A., Iizuka, T., Stirling, C. H., Ireland, T. R., Petaev, M., Jacobsen, S. B., 2010. U-Pb chronology of the Solar System's oldest solids with variable ${ }^{238} \mathrm{U} /{ }^{235} \mathrm{U}$. Earth and Planetary Science Letters 300 (3-4), 343-350.

Brennecka, G. A., Wadhwa, M., 2012. Uranium isotope compositions of the basaltic angrite meteorites and the chronological implications for the early solar system. Proceedings of the National Academy of Sciences 109 (24), 9299-9303.

Burnett, D. S., Jurewicz, A. J. G., Woolum, D. S., Wang, J., Paque, J. M., Nittler, L. R., McKeegan, K. D., Humayun, M., Hervig, R., Heber, V. S., Guan, Y., 2015. Ion implants as matrix-appropriate calibrators for geochemical ion probe analyses. Geostandards and Geoanalytical Research 39 (3), 265-276.

Chambers, J. M., 1992. Linear models. Wadsworth and Brooks.

Coath, C. D., Steele, R. C. J., Lunnon, W. F., 2013. Statistical bias in isotope ratios. Journal of Analytical Atomic Spectrometry 28 (1), 52-58.

Connelly, J. N., Bizzarro, M., Krot, A. N., Nordlund, Å., Wielandt, D., Ivanova, M. A., 2012. The absolute chronology and thermal processing of solids in the solar protoplanetary disk. Science 338 (6107), 651-655.

de Leuw, S., Rubin, A. E., Schmitt, A. K., Wasson, J. T., 2009. ${ }^{53} \mathrm{Mn}-{ }^{53} \mathrm{Cr}$ systematics of carbonates in $\mathrm{cm}$ chondrites: Implications for the timing and duration of aqueous alteration. Geochimica et Cosmochimica Acta 73 (24), 7433-7442. 
Doyle, P. M., Jogo, K., Nagashima, K., Huss, G. R., Krot, A. N., 2016. Mn-Cr relative sensitivity factor in ferromagnesian olivines defined for SIMS measurements with a Cameca ims-1280 ion microprobe: Implications for dating secondary fayalite. Geochimica et Cosmochimica Acta 174, 102-121.

Endress, M., Zinner, E., Bischoff, A., 1996. Early aqueous activity on primitive meteorite parent bodies. Nature 379 (6567), 701-703.

Endress, M., Zinner, E., Weber, D., Bischoff, A., 1994. New constraints on the formation history of carbonates in the CI chondrite Ivuna from the Mn-53-Cr-53 chronometer: Preliminary results. Meteoritics 29, 463.

Friedman, A., Milsted, J., Metta, D., Henderson, D., Lerner, J., Harkness, A., et al., 1966. Alpha Decay Half Lives of ${ }^{148} \mathrm{Gd}{ }^{150} \mathrm{Gd}$ and ${ }^{146} \mathrm{Sm}$. Radiochimica Acta 5 (4), 192-194.

Fujiya, W., Sugiura, N., Hotta, H., Ichimura, K., Sano, Y., 2012. Evidence for the late formation of hydrous asteroids from young meteoritic carbonates. Nature Communications 3,16.

Fujiya, W., Sugiura, N., Sano, Y., Hiyagon, H., 2013. Mn-Cr ages of dolomites in CI chondrites and the Tagish Lake ungrouped carbonaceous chondrite. Earth and Planetary Science Letters 362 (0), 130-142.

Glavin, D. P., Kubny, A., Jagoutz, E., Lugmair, G. W., 2004. Mn-Cr isotope systematics of the D’Orbigny angrite. Meteoritics \& Planetary Science 39 (5), 693-700.

Heber, V. S., McKeegan, K. D., Burnett, D. S., Duprat, J., Guan, Y., Jurewicz, A. J., Olinger, C. T., Smith, S. P., 2014. Accurate analysis of shallowly implanted solar wind ions by SIMS backside depth profiling. Chemical Geology 390, 61 - 73.

Honda, M., Imamura, M., 1971. Half-Life of ${ }^{53}$ Mn. Phys. Rev. C 4 (4), 1182-1188.

Hoppe, P., MacDougall, D., Lugmair, G. W., 2007. High spatial resolution ion microprobe measurements refine chronology of carbonate formation in Orgueil. Meteoritics $\mathcal{E}$ Planetary Science 42 (7-8), 1309-1320. 
Hutcheon, I. D., Krot, A. N., Keil, K., Phinney, D. L., Scott, E. R. D., 1998 ${ }^{53}$ Mn- ${ }^{53}$ Cr dating of fayalite formation in the CV3 chondrite Mokoia: Evidence for asteroidal alteration. Science 282 (5395), 1865-1867.

Hutcheon, I. D., Phinney, D. L., 1996. Radiogenic ${ }^{53}$ Cr* in Orgueil Carbonates: Chronology of Aqueous Activity on the CI Parent Body. In: Lunar and Planetary Institute Science Conference Abstracts. Vol. 27. p. 577.

Hutcheon, I. D., Weisberg, M. K., Phinney, D. L., Zolensky, M. E., Prinz, M., Ivanov, A. V., 1999. Radiogenic ${ }^{53} \mathrm{Cr}$ in Kaidun Carbonates: Evidence for Very Early Aqueous Activity. In: Lunar and Planetary Science Conference. Vol. 30 of Lunar and Planetary Science Conference. p. 1722.

Inghram, M. G., 1954. Stable isotope dilution as an analytical tool. Annual review of nuclear science $4(1), 81-92$.

Ireland, T., 1995. Ion microprobe mass spectrometry: techniques and applications in cosmochemistry, geochemistry, and geochronology. Advances in analytical geochemistry 2, $1-118$.

Ireland, T., Clement, S., Compston, W., Foster, J., Holden, P., Jenkins, B., Lanc, P., Schram, N., Williams, I., 2008. Development of shrimp. Australian Journal of Earth Sciences 55 (67), 937-954.

Ito, M., Ganguly, J., 2006. Diffusion kinetics of $\mathrm{Cr}$ in olivine and ${ }^{53} \mathrm{Mn}-{ }^{53} \mathrm{Cr}$ thermochronology of early solar system objects. Geochimica et Cosmochimica Acta 70 (3), 799-809.

Jilly, C. E., Huss, G. R., Krot, A. N., Nagashima, K., Yin, Q.-Z., Sugiura, N., $2014 .{ }^{53} \mathrm{Mn}-{ }^{53} \mathrm{Cr}$ dating of aqueously formed carbonates in the CM2 lithology of the Sutter's Mill carbonaceous chondrite. Meteoritics $\mathcal{E}$ Planetary Science 49 (11), 2104-2117.

Jilly, C. E., Huss, G. R., Nagashima, K., 2013. Mn-Cr Dating of Secondary Carbonates in CR Chondrites. In: Lunar and Planetary Institute Science Conference Abstracts. Vol. 44 of Lunar and Planetary Institute Science Conference Abstracts. p. 2474. 
Jochum, K. P., Weis, U., Stoll, B., Kuzmin, D., Yang, Q., Raczek, I., Jacob, D. E., Stracke, A., Birbaum, K., Frick, D. A., Günther, D., Enzweiler, J., 2011. Determination of reference values for NIST SRM 610-617 glasses following ISO guidelines. Geostandards and Geoanalytical Research 35 (4), 397-429.

Jogo, K., Nakamura, T., Noguchi, T., Zolotov, M. Y., 2009. Fayalite in the vigarano CV3 carbonaceous chondrite: Occurrences, formation age and conditions. Earth and Planetary Science Letters 287 (3-4), 320 - 328.

Kinoshita, N., Paul, M., Kashiv, Y., Collon, P., Deibel, C. M., DiGiovine, B., Greene, J. P., Henderson, D. J., Jiang, C. L., Marley, S. T., Nakanishi, T., Pardo, R. C., Rehm, K. E., Robertson, D., Scott, R., Schmitt, C., Tang, X. D., Vondrasek, R., Yokoyama, A., 2012. A shorter ${ }^{146} \mathrm{Sm}$ half-life measured and implications for ${ }^{146} \mathrm{Sm}-{ }^{142} \mathrm{Nd}$ chronology in the solar system. Science 335 (6076), 1614-1617.

Kutschera, W., Billquist, P. J., Frekers, D., Henning, W., Jensen, K. J., Xiuzeng, M., Pardo, R., Paul, M., Rehm, K. E., Smither, R. K., Yntema, J. L., Mausner, L. F., 1984. Half-life of ${ }^{60} \mathrm{Fe}$. Nuclear Instruments and Methods in Physics Research B 5, 430-435.

Leta, D. P., Morrison, G. H., 1980. Ion implantation for in-situ quantitative ion microprobe analysis. Analytical Chemistry 52 (2), 277-280.

Matzel, J., Jacobsen, B., Hutcheon, I. D., Kita, N., Ryerson, F. J., 2009. Influence of bulk chemical composition on relative sensitivity factors for ${ }^{55} \mathrm{Mn} /{ }^{52} \mathrm{Cr}$ by sims: Implications for the ${ }^{53} \mathrm{Mn}-{ }^{53} \mathrm{Cr}$ chronometer. AGU Fall meeting 1, 06.

McKeegan, K. D., Davis, A. M., 2003. Early Solar System Chronology. Treatise on Geochemistry $1,431-460$.

McKibbin, S. J., Ireland, T. R., Amelin, Y., Holden, P., 2015. Mn-Cr dating of Fe- and Carich olivine from 'quenched'and 'plutonic'angrite meteorites using Secondary Ion Mass Spectrometry. Geochimica et Cosmochimica Acta 157, 13-27. 
McKibbin, S. J., Ireland, T. R., Amelin, Y., Holden, P., Sugiura, N., 2013a. A re-evaluation of the $\mathrm{Mn}-\mathrm{Cr}$ systematics of olivine from the angrite meteorite D'Orbigny using secondary ion mass spectrometry. Geochimica et Cosmochimica Acta 123 (0), 181-194.

McKibbin, S. J., Ireland, T. R., Amelin, Y., O’Neill, H. S. C., Holden, P., 2013b. Mn-Cr relative sensitivity Factors for Secondary Ion Mass Spectrometry analysis of $\mathrm{Mg}-\mathrm{Fe}-\mathrm{Ca}$ olivine and implications for the $\mathrm{Mn}-\mathrm{Cr}$ chronology of meteorites. Geochimica et Cosmochimica Acta 110 (0), 216-228.

Meissner, F., Schmidt-Ott, W.-D., Ziegeler, L., 1987. Half-life and $\alpha$-ray energy of ${ }^{146} \mathrm{Sm}$. Zeitschrift für Physik A Atomic Nuclei 327 (2), 171-174.

Nyquist, L. E., Kleine, T., Shih, C. Y., Reese, Y. D., 2009. The distribution of short-lived radioisotopes in the early solar system and the chronology of asteroid accretion, differentiation, and secondary mineralization. Geochimica et Cosmochimica Acta 73 (17), 51155136.

Ogliore, R. C., Huss, G. R., Nagashima, K., 2011. Ratio estimation in sims analysis. Nuclear Instruments and Methods in Physics Research Section B: Beam Interactions with Materials and Atoms 269 (17), 1910-1918.

Papathanassiou, A., 1998. Effect of hydrostatic pressure on the electrical conductance of polycrystalline magnesite $\left(\mathrm{MgCO}_{3}\right)$. Physical Review B 58 (8), 4432.

Papathanassiou, A. N., Grammatikakis, J., 1996. Pressure variation of the electrical conductivity of dolomite $\mathrm{CaMg}\left(\mathrm{CO}_{3}\right)_{2}$. Phys. Rev. B 53, 16247-16251.

Petitat, M., Marrocchi, Y., McKeegan, K., Mostefaoui, S., Meibom, A., Zolensky, M., Gounelle, M., 2011. ${ }^{53} \mathrm{Mn}-{ }^{53} \mathrm{Cr}$ ages of kaidun carbonates. Meteoritics \& Planetary Science 46 (2), 275-283.

Petitat, M., McKeegan, K., Gounelle, M., Mostefaoui, S., Marrocchi, Y., Meibom, A., Leshin, L., 2009. Duration and sequence of carbonate crystallization on the orgueil protolith: ${ }^{53} \mathrm{Mn}-$ ${ }^{53} \mathrm{Cr}$ systematics of their evolution in $\mathrm{O}$ and $\mathrm{C}$ isotopic composition. Lunar Planet. Sci 40, 1657. 
R Core Team, 2013. R: A Language and Environment for Statistical Computing. R Foundation for Statistical Computing, Vienna, Austria.

Rugel, G., Faestermann, T., Knie, K., Korschinek, G., Poutivtsev, M., Schumann, D., Kivel, N., Günther-Leopold, I., Weinreich, R., Wohlmuther, M., 2009. New Measurement of the ${ }^{60}$ Fe Half-Life. Physical Review Letters 103 (7), 1-4.

Smith, D. H., Christie, W. H., 1978. A comparison of a theoretical model and sensitivity factor calculations for quantification of sims data. International Journal of Mass Spectrometry and Ion Physics 26 (1), 61-76.

Steele, R. C. J., Elliott, T., Coath, C. D., Regelous, M., 2011. Confirmation of massindependent Ni isotopic variability in iron meteorites. Geochimica et Cosmochimica Acta 75 (24), 7906-7925.

Sugiura, N., Ichimura, K., Fujiya, W., Takahata, N., 2010. Mn/Cr relative sensitivity factors for synthetic calcium carbonate measured with a nanosims ion microprobe. Geochemical Journal 44 (6), 11.

Sugiura, N., Miyazaki, A., Yanai, K., 2005. Widespread magmatic activities on the angrite parent body at 4562 Ma ago. Earth Planets Space 57 (9), e13-e16.

Telford, W. M., Sheriff, R. E., 1990. Applied geophysics. Vol. 1. Cambridge university press.

Trinquier, A., Birck, J. L., Allègre, C. J., Göpel, C., Ulfbeck, D., 2008. ${ }^{53} \mathrm{Mn}-{ }^{53} \mathrm{Cr}$ systematics of the early Solar System revisited. Geochimica et Cosmochimica Acta 72 (20), 5146-5163.

Venables, W. N., Ripley, B. D., 2002. Modern applied statistics with S. Springer.

Wilkinson, G., Rogers, C., 1973. Symbolic description of factorial models for analysis of variance. Applied Statistics, 392-399.

Yoneda, S., Nagamine, T., Oura, Y., Ebihara, M., 2002. Precise Determination of the Mn53/Mn-55 Isotopic Ratio in the ALH77250 Iron Meteorite. Bull Natl Sci Mus Ser E 25, $7-14$. 
Ziegler, J. F., 2004. Srim-2003. Nuclear Instruments and Methods in Physics Research Section 764 B: Beam Interactions with Materials and Atoms 219-220 (0), 1027-1036.

765 Zinner, E., Walker, R. M., 1975. Ion-probe studies of artificially implanted ions in lunar sam766 ples. In: Lunar and Planetary Science Conference Proceedings. Vol. 6 of Lunar and Plane$767 \quad$ tary Science Conference Proceedings. pp. 3601-3617. 